\title{
The Development of Social Climate in Virtual Learn- ing Discussion Groups
}

Avigail Oren

Tel-Aviv University, School of Education

David Mioduser

Tel-Aviv University, School of Education

Rafi Nachmias

Tel-Aviv University, School of Education

\begin{abstract}
As the educational use of computer mediated communication (CMC) increases there is growing interest among researchers as to social processes evolving within the varied models of group work using Internet, e.g., special interest groups, topical discussion groups, discussion forums attached to virtual courses, and learning communities. In this paper we present a synthetic summary of five studies that explored social climate issues in synchronous and asynchronous online activities in academic courses, focusing on the following questions: Does a social atmosphere develop in online learning discussion groups? What are the different modes of social interaction are manifest in online learning discussion groups? What is the role of the virtual teacher with regards to the social climate in online learning discussion groups? Discussed are the implications of these five studies' on the design of virtual-learning-discussion-groups, and the results for the characterization of teacher moderation functions.
\end{abstract}

\section{INTRODUCTION}

As the educational use of computer mediated communication (CMC) increases there is growing interest among researchers as to the social processes manifest within the varied models of group work using Internet, e.g., special interest groups, topical discussion groups, discussion forums attached to virtual courses, and learning communities. However, despite the researchers' agreement on the important contribution of social activity to virtual learning processes (see Harasim, 1990 ; Hiltz, 1995; Anderson \& Kanuka, 1997; Wegerif, 1998; Chan \& Rapman, 1999; Bonk et al., 2000; Sherry, 2000), major issues regarding the social function of virtual groups still deserve in-depth study.

In an attempt to contribute to the understanding of virtual social processes, this article presents a synthetic summary of five studies carried out at Tel-Aviv University's School of Education that explored social climate issues in synchronous 
and asynchronous online academic courses. In the following sections we briefly refer to related research, summarize the main findings of the five studies, and integrate these findings in the subsequent discussion of salient issues related to social climate in virtual learning discussion groups.

There is no doubt today that among its many functions the Internet fulfills a powerful social role. Perceived as a social meeting place, it provides opportunities for the development of new modes of interpersonal relationship (Parks \& Floyd, 1996). The Web is used for numerous purposes, such as extending one's social network, participating in online virtual communities, finding a marriage partner, and developing successful business relationships. Thus, for Internet users, traditional face-to-face interaction has been complemented by a technology that creates new social genres of interpersonal transaction, and new configurations of group work.

Research on learning processes in face-to-face groups indicates that development of social climate is important in order to make students feel like insiders in the learning environment, thus contributing to students' motivation, involvement and contentment (Chan \& Rapman, 1999; Wegerif, 1998). Regarding social climates in virtual groups, early studies dealing with computer mediated relationships led to the conclusion that the network does not contribute to the creation of a social climate. Because the nature of electronic meetings are anonymous and lack environmental features such as physical appearance, non-verbal cues of face-to-face meetings (Sproull \& Kiesler, 1991), they were found not to support the development of interpersonal relationships. It was also claimed that in comparison with face-to-face meetings, the relationships established via online communication are more hostile, divisive and uninhibited (Kiesler \& Sproull, 1992).

Recent work, however, has raised serious theoretical and empirical challenges to this pessimistic view of Internet-based social relations. Walther (1996) pointed out that perceptual changes of the Internet as a platform for establishment of social relationships, began with the observation that many of the differences between computer mediated and face-to-face interaction, diminished over time. When limitations of time are removed and long term processes are observed, online social groups report levels of commitment and affiliation similar to faceto-face groups. Walther, Anderson and Park (1994) suggested that Internetbased relationships are more intimate and intensive than those maintained in face-to face settings. It appears that one of the apparent disadvantages of the online relationship, namely anonymity, in fact facilitates self-disclosure without taking risks. It facilitates exploration of diverse perspectives by adopting alternative identities, e.g., the opposite gender, or a rival point of view (Turkle, 1995). Burgules (in press) even refers to these not as false identities, but as extrapolations of aspects of people's actual identities that can now be safely disclosed with the mediation of the technology. This mode of communication also serves as a springboard for formation of intensive, pleasurable, deep and

International Review of Research in Open and Distance Learning 
rich interpersonal connections. In addition, it offers the possibility to abandon obviously distasteful or unsuitable connections, as well as opportunities to enter into simultaneous relationships with a number of people (Schnarch, 1997).

The unique characteristics of Internet-mediated communications have also contributed to the development of novel and varied configurations of group work, from ad-hoc discussion groups to comprehensive learning communities. These models actually imply an expansion and even a transformation of variables, components and processes that characterize traditional collaborative learning (Sharan, 1994). Effects of the use of the technology can be found at a variety of levels, e.g., regarding the setting of the activity (e.g., asynchronous, non faceto-face interactions); the dynamics of the interactions (e.g., dynamic definition of ad-hoc roles and functions within a group); the configuration of the group (e.g., occasional participation according to emerging needs); and the variety of communication means used for interacting (e.g., email, chat, collaborative-work tools).

Summarizing the above brief (and partial) survey on social aspects of the Internet we can conclude that: (a) the Internet's characteristics facilitate the development of unique forms of interpersonal and group interaction; (b) recognizing this potential, educators have developed a wide range of models of integration of the technology into group learning processes; (c) there is a growing interest in the social aspects of virtual learning groups; (d) opinions differ as regards to the role of the technology in the creation of the social climate of learning groups; and (e) more research is needed for a better understanding of social processes in virtual learning groups.

In line with these conclusions, the purpose of this article is to report on the findings of a series of studies conducted at Tel-Aviv University's School of Education. The rest of this article comprises two main sections. In the first section, we summarize the results of five studies conducted to explore different social aspects of learning synchronous and asynchronous online learning activities. In the second section we integrate these research results into a discussion of the following questions:

1. Does a social climate develop at all in online learning discussion groups?

2. What modes of social interaction evolve in online learning discussion groups?

3. What is the role of the virtual teacher with regards to the social atmosphere in online learning discussion groups? 


\section{THE STUDIES}

Five studies were conducted to examine various aspects of the social climate of virtual discussion groups engaged in online courses (both virtual and combined virtual / face-to-face courses). Figure 1 graphically organizes the different aspects of the groups; work considered in the studies. Although the virtual group is a social system characterized by intimate interactions among all its components, each study focused on separate aspects: the social or organizational issues implicit in the social content of students' messages (Study 1); the (real or pretended) identity students and teachers assumed while participating in online discussions (Study 2); the discussion moderation abilities and strategies within the social climate as a whole (Study 3); social interactions among students and teachers in terms of verbal patterns (Study 4); and evolving informality (Study $5)$.

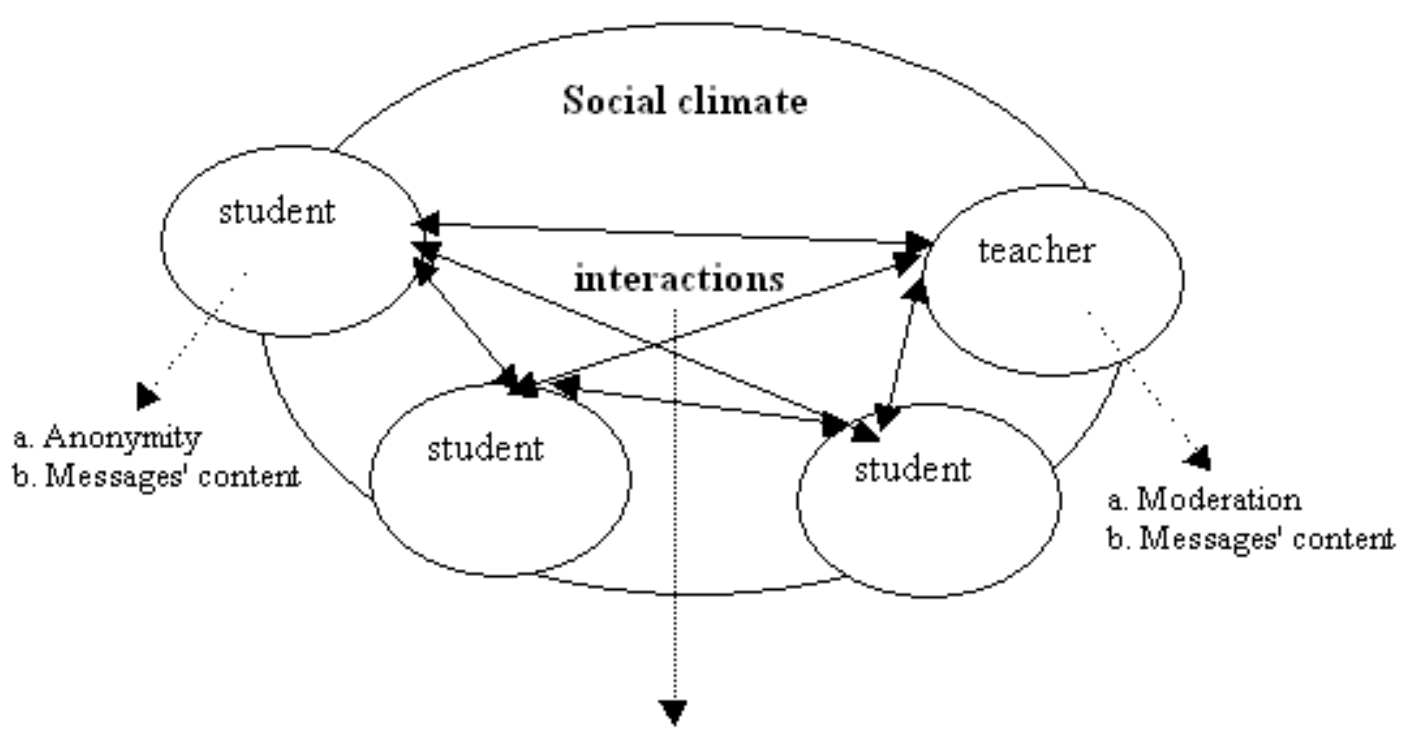

a. Verbal patterns

b. Content

- Subject matter

- Social

- Organizational 
Figure 1: Social Aspects of Learning Discussion Groups in the Reported Studies

\section{STUDY 1: CONTENT AND SOCIAL MESSAGES IN ASYNCHRONOUS DISCUSSION GROUPS}

The purpose of this study was to explore the interactions among students in asynchronous learning discussion groups, in particular as to whether these interactions deal with subject matter or social issues (Rozner, 2000).

\section{Method}

Eight groups, each including two to four high school students from different schools, were enlisted in a reading encouragement project. Students were asked to read the same book and then participate in a discussion group moderated by a teacher. The total of 83 messages were classed into 156 units of meaning. The classing of the units was done following Henri's (1991) model based on content analysis of online messages, looking for significant units pertaining to one of five categories: participation, social, interaction, cognitive, and meta cognitive units. Subsequently, identified units were divided into content discussion units (CDU) and social discussion units (SDU). CDUs were explored in depth to find whether and how knowledge construction evolved through the project.

\section{Results}

The results showed that the teacher, who controlled the discussion, sent 40 percent of the messages. The teacher encouraged students to focus on the learning assignment and to send long messages. The average percentage of SDUs for all four sessions was 33 percent. At the beginning of the learning process the percentages of CDU and SDU were similar, and in two groups there were more SDU than CDU. But as time passed the number of CDU increased and of SDU decreased. The students actually focused on the learning assignments, and gradually most of the units in their messages were CDUs.

As the teacher was not engaged in creating a learning group, but instead focused mainly on the learning assignment, students felt that their activity in the discussion forum should only fulfill the assignments. Consequently, social interaction was limited, students interacted more with the teacher than with each other, and the objective of collaborative knowledge construction was not accomplished. Nevertheless social interaction was not totally absent. Social units could still be found in messages such as: "We enjoyed exchanging messages with you. We noted that you really like sport." "We are happy that you 
would like us to keep in touch, we send you our addresses." "Already two weeks passed and we have not got a response. It is not fun to write and not to get a response."

\section{STUDY 2: THE INFLUENCE OF STUDENT ANONYMITY AND TEACHER GUIDANCE ON THE SOCIAL AND COGNITIVE NATURE OF AN EDUCATIONAL SYNCHRONIC ENVIRON- MENT}

In this study the learning process in a synchronous environment (chat) was explored. The research questions dealt with the influence of anonymity and moderation on virtual conferences (Tsur, 2000).

\section{Method}

Eleven grade eight students participated in 12 online discussions (chats) in four different situations: moderated or non-moderated by an instructor, and using or not using names or nicknames. The study's data were the whole set of interactions, and students' answers to a summarizing questionnaire.

Content messages were defined as messages focusing on the academic subjects discussed, while social messages were defined as messages comprising polite sentences (e.g., from the "hi-bye" genre) or sentences that otherwise do not relate to the content (e.g., "Does it rain now where you are?")

\section{Results}

The findings indicated that in this academic conferencing situation, more task oriented sentences occur than social sentences. Moderation as such had no effect on the quantity of sentences of either type, content or social. Regarding anonymity, more content related messages were found in interactions with nicknames than in interactions with real names $\left(F=6.2 ; p_{i} 0.05\right)$. In non-moderated discussions, as well, more content messages were delivered when nicknames were used, than when real names were used $(F=5.76 ; p ; 0.05)$.

There was no significant difference relating to social cues. But the following findings are of particular interest. First, the amount of social sentences was similar to the amount of content sentences when students used real names and the discussion was not moderated. In addition, the highest amount of social 
sentences was generated when students used nicknames and the discussion was not moderated. When the discussion was moderated the number of negative social sentences decreased.

When asked about their attitude towards moderation, only two students out of 11 were firmly positive. Others said: "Without a moderator it is more fun, as we talk among ourselves." "The moderator tells us to hurry and it is no good." "I think that it should be possible to express your opinion freely, and a moderator only hinders."

When asked about anonymity only one student out of 11 was firmly against. Other opinions were: "It is more convenient to speak with a nickname." "I could say all I wanted, it is cooler." "The student has not to fear that tomorrow morning somebody will say this student said so and so." Anonymity was detected as a factor that encourages the participation of the whole group, in contrast to a face-to-face situation where typically some students do not take part in the discussion.

\section{STUDY 3: THE DEVELOPMENT OF SOCIAL CLIMATE IN ASYNCHRONOUS CONFERENCES}

This study examined whether a social climate evolves in online courses of different kinds: a hybrid course (a mixture of online and face-to-face interactions) and a distance learning course (Sheri-Steinberg, 2000). Both courses offered a virtual cafeteria as a social forum, in addition to other forums in which course subjects were discussed. The study focused on the "strength of social climate" emerging in the social discussion-forums, and in the content discussion-forums, of both types of courses.

\section{Method}

Content analysis of 355 messages posted by students participating in two distancelearning courses (one delivered mostly online and the other in a mixed face-toface and online discussion mode) was performed. Messages were classified as relating either to the course content or to social issues (e.g., as those occurring in the virtual cafeteria forum). Social expressions were classified as personally addressed, as directed to the whole group, or not addressed at all. Finally, the strength of social climate for each student was calculated by dividing the number of social expressions by the total number of messages generated. The whole set of data was analyzed to identify differences in social climate parameters among modes of learning and kinds of discussion forums.

International Review of Research in Open and Distance Learning 


\section{Results}

Results indicate that the strength of the social climate in the online cafeteria used by distance learning students was higher $(M=0.82)$ than the strength of social climate in the online cafeteria used by face-to-face students $(M=0.39)$. In the content discussion forums, the social strength was higher in the face-to-face group $(M=1.41)$ than in the distance-learning group $(M=0.8)$; the difference was significant $\left(F=6.37, p_{i} 0.05\right)$. Analysis of social climate at different periods in time shows that only in the distance-learning course in the virtual cafeteria forum did the strength of social climate progressed over time $\left(t=1.33, p_{i} 0.05\right)$.

Apparently, face-to-face students had a real cafeteria to develop communication. As time passed and they began to know each other personally, the virtual social place became less important. In contrast, virtual students had to use the virtual cafeteria throughout their course in order to communicate both about their studies and socially. Moreover, it was interesting to find that online students in need of social interaction, embedded their social interactions within the content discussion forums.

\section{STUDY 4: VERBAL INTERACTION PATTERNS IN MUD CLASSES}

This study dealt with the educational potential of text-based virtual environments, in this case in a multiple users domain (MUD) (Daher, 2000). The main research assumption was that communication patterns in a MUD classroom are different from communication patterns in the traditional classroom. The study focused on the patterns of both teacher-student and student-student verbal interactions in a MUD class, compared with those in a traditional class and an audio-video conference.

\section{Method}

Logs of English language discussions between four teachers and 32 students were analyzed, using an instrument based on the models by Amidon and Flanders (1967). The instrument defined three basic categories of teacher-student interactions: teacher-initiated and student-initiated interactions, and student-student interactions.

The data collected were compared to findings on verbal interaction in the traditional class as reported by Pankraz (1967) and Flanders (1967), and to parallel findings from an audio-video conference class as reported by Murphy (1995).

International Review of Research in Open and Distance Learning 


\section{Results}

In comparison with results reported for traditional and audio-video conference classes, we found that in the MUD classes:

- The proportion of teacher talk was lower than in the other two types of classes.

- The proportion of student talk was higher.

- Teachers' response (i.e., acceptance or rejection of students' talk) was minimal.

- The ratio of student initiated talk in teacher-student verbal interaction was lower.

- The ratio of student responses and initiated talk in student-to-student verbal interaction was higher.

- The ratio of teacher questions was the same as in the traditional class, and higher than in the audio-video conference class.

Although it seems that teachers in a MUD environment participated in discussions to a lesser extent than in a face-to-face class, they still played a dominant role. The teacher-students interaction pattern prevailed over the studentstudent interaction pattern. In contrast, students did not initiate talks with an unresponsive teacher preferring to initiate talks with each other.

\section{STUDY 5: INFORMAL VIRTUAL MEETING SPACES}

The goal of this study was to closely trace the development of social interactions in informal virtual spaces that were offered as components of the environment of a distance learning course (Oren, 2001).

\section{Method}

Participants were a group of teachers ( $\mathrm{T}$ group) in a distance learning course $(n=14)$, and university students ( $\mathrm{U}$ group) in a combined face-to-face and distancelearning course $(n=19)$. An informal virtual meeting place - a "cafeteria" - was established to support social interaction. In the middle of the term another social forum was established "the corridor" - especially for help functions. Messages delivered in these forums were counted and their content was analyzed. Content analysis looked for issues that engaged students in these forums.

International Review of Research in Open and Distance Learning 


\section{Results}

During the first six weeks of the courses, a large number of messages were posted in the cafeteria forum ( $\mathrm{T}$ group, 77 messages; $\mathrm{U}$ group, 137 messages). At first most notes focused on social issues (e.g., acquaintance), but gradually the forum became a place where students also exchanged information regarding organizational issues. To support this growing need another forum was created, the corridor forum, defined as a place where people meet incidentally and have the possibility to post notes on various topics (e.g., technical issues, difficulties with a bibliographical item, arrangements for a virtual meeting) and to request the instructor's or another students' reply. Following the corridor's creation, 19 messages were posted in it by the T group during its first month, and 39 by the $\mathrm{U}$ group already in its first week. In contrast in the same periods, 13 messages were posted in the cafeteria forum by the $\mathrm{T}$ group, and 11 by the $\mathrm{U}$ group.

It seems evident that the students perceived support for the organizational aspects of the group's functioning as an important need. They created a de facto space for this kind of interaction within another existing space (the cafeteria), and took full advantage of the new space when offered to them. The possibility to collectively handle technical and organizational aspects of the group's life appeared to be an important element for sustaining the social existence of the learning group.

Examples of the messages that were posted to the corridor forum are: "I am looking for a mate to prepare the assignment together...You may contact me via email, ICQ or here." "If somebody finds Ellis in the corridor, tell her to" "(Ellis): I walked in the corridor and have seen your message."

It seems that as far as social interaction evolves in a learning group, it did does not appear to matter whether a course is delivered wholly or only partly online. Students needed the acquaintance phase, to have small talk, and to discuss problems - technical or methodological - arising in the course of learning.

\section{DISCUSSION}

Each study described in the previous section concerned a particular social aspect of discussion groups in online courses. In this section we will integrate these results to elaborate on the three issues raised in the introduction of this paper, namely the development of social climate, the emerging modes of social interaction, and the role of the teacher regarding social atmosphere in learning discussion groups. 


\section{Does social climate develop in online learning discussion groups?}

A crucial question regarding online discussion groups is if and how a social climate develops within an online environment, considered by some as a "cold medium," i.e., alienating and lacking the warmth of intonations, inflections, gestures and body language characterizing face-to-face interactions. The findings of our studies refute this characterization of technology-mediated interactions. The results show that in all discussion groups a social activity layer gradually developed, fulfilling an important role by supporting the learning group's work, as evidenced in the contents of more than one third of the messages in an asynchronous environment (Study 1), and almost one third of the messages in a synchronous environment (Study 2). The strength of the social climate as reflected in the discussion forums increased with time not only in the forums defined as social spaces (e.g., cafeteria) but in content-related forums as well (study 3).

A key question to be asked here relates to the nature of this social layer. In the context of face-to-face group learning and work processes, social issues have been studied extensively (Sharan, 1994). This is not yet the case for virtual groups. Based on our and other observations we can draw several conclusions regarding significant changes in the group's functioning within virtual environments in comparison with face-to-face groups, for example:

- Group activities are not limited by place or time boundaries, and group members communicate whenever convenient for them, thus contributing to the creation of a learning atmosphere free from pressure and compulsion, and enabling the emergence of social interactions as well as completion of learning assignments (see Studies 1 and 5). In asynchronous work, members' participation proceeds through differentiated stages separated in time, e.g., reading, elaboration, production, delivery, and feedback supply or feedback recollection stages. A crucial implication is that a member's input to the group's work can be elaborated without the pressing immediacy so typical of face-to-face communication situations.

- Group members can assume various roles and even (in less formally defined situations) various identities according to changing situations (see Study 2 ). Anonymity supports the appearance of social relations and even affects the accomplishment of the learning assignments as well.

- Human necessity to communicate promotes, when using the technology, a process in which new symbolic conventions and communication codes are gradually developed (see Study 4). Virtual transactions involve a process of translation of physical gestures (an essential component of any face-toface interaction) into digital gestures (e.g., emoticons), resulting gradually in the consolidation of new conventions and communication codes.

International Review of Research in Open and Distance Learning 
Our findings reinforce the claims in the research literature that the Internet clearly supports the development of new modes of social interaction (digital social climate), even expanding the opportunities for these beyond the constraints of space and time. Early concerns about the alienating nature of technologybased interactions (Kiesler \& Sproull, 1992) were not supported, or better put, they were strongly contradicted by the dense and multifaceted social life evolving on the Internet. In relation to educational issues, we observed that these social interactions in virtual learning groups were strongly intertwined with learning interactions, and that particular functional needs evolved at the social level as the groups' work proceeded in time.

\section{What modes of social interaction evolve in online discussion groups?}

Among individual students or the whole group, social behavior in virtual groups typically takes the form of an exchange of friendly texts not directly related to the learning activity (Harasim, 1990; Henri, 1991; Hiltz, 1995, Oren et. al, 2000; Hara, Bonk \& Angeli, 2000). An analysis of texts generated by discussion groups illustrated the emergence of different modes of social behavior: strictly social, content-related, and functional.

The first mode can be observed in messages that are delivered in forums dedicated to social interaction per se, and are detached from the learning task or the content under discussion. The second mode is evident in content-related messages that also include explicit social components. The context for the interaction is a learning task, but besides formal statements messages also contains expressions aimed to offer guidance, support or personal feedback to its recipient.

Our studies (Studies 1 and 3) and similar ones (e.g., Hara et al., 2000), showed that the number of messages not related to content issues (namely social-only) decreased as the semester progressed. At the same time, the gradual consolidation of the social climate can be recognized in the language and style of content-related messages. As time passed, students began to refer to each other by their first name or nickname (e.g., Moses the Shark). They also began to use emotional language in evaluating each other's work (e.g., "Good for you." "I like it." "I enjoyed it." "I loved it." "I totally agree with your opinion." "Thanks for the idea.") Messages became more friendly and personal. When at the end of the course students were asked about the social climate in the course, they mentioned it was exciting and that personal ties evolved over time. For example, referring to a collaborative assignment in which each student had to look for a partner and complete a project, one participant wrote that "We began by asking - would you like to work with me? And in the end we all knew each other's families."

International Review of Research in Open and Distance Learning 
The third mode of social interactions has mainly functional purposes. It refers to the participants' practical needs, whether or not these are related to specific learning tasks (e.g., information about the classes, location of resources, or even events unrelated to the courses). Our observations in the studies reported in this paper reinforce previous claims regarding the importance of special virtual places for students to maintain functional communication (Harasim et. al, 1995). In these previous studies, the importance of informal or incidental meeting places was stressed both by the instructors and students participating in virtual courses. However, it appears that the nature of the course (virtual or combined face-to-face/virtual) affects the quality and intensity of use of these functional virtual meeting places. In Study 5 we observed that in a virtual-only course, the students made frequent use of the informal meeting space (the cafeteria). Moreover, as the course advanced the demand for an additional functional space focusing on organizational aspects (the corridor) was raised. In contrast, in courses that included online activities as part of the traditional learning, the need for special informal meeting virtual places decreased over time (see study 3). For face-to-face groups, meetings in "real" cafeterias and the continuous personal interaction in the classes diminished the social role of the virtual meeting places.

\section{What is the role of the virtual teacher in regard to the social atmosphere developed in a virtual group?}

Our studies revealed that teachers' involvement, or more accurately a decrease in teachers' involvement in the discussion is an important factor in the development of social climate in virtual discussion groups. Despite educators' unanimous statements favoring the constructivist approach to learning, teacher controlled learning is still the most common mode of instruction in schools (Varsidais, 2000). Likewise, despite the widespread view that the constructivist and collaborative approaches are the most appropriate modes for managing online discussion groups, the lecturing mode often remains the most common strategy used by instructors to moderate virtual discussions. Conventional pedagogy tends to creep into the new learning environments (Nachmias et al., 2000). This situation explains research results indicating that an increase in students' participation and in social activity was correlated with a decrease in teachers' control over the group's work (Sotillo, 2000; also Study 1).

In Study 1 it was obvious that the moderating strategy that urged students to focus on the learning assignments caused a decrease in social interaction. At the beginning of the course the number of social units of meaning was almost equal to the number of content units of meaning; as a consequence of the teachers' mode of instruction, social verbal behavior decreased. The same trend appeared in Study 2: social interaction developed more easily when students felt free, i.e., when they were not moderated and they were using nicknames. Even in the

International Review of Research in Open and Distance Learning 
MUD environment (Study 4), where teacher dominance was lower and student participation was higher than in traditional classes, students still interacted more with the teacher than with their peers because of the perceived pressure to complete the learning task. It is evident that while the development of a social climate is quite a natural need of the students in online discussions, it may either grow or vanish as a function of the moderation and intervention approach of the virtual teacher.

\section{IMPLICATIONS OF THESE STUDIES}

This article summarizes a series of studies carried out at Tel Aviv University's School of Education that examined the development of social climate in virtual discussion groups. To sum up, we will to relate our observations for the development and implementation of online courses. The practical implications pertain to: awareness, support, pedagogical rationale, teacher training, student training, and research.

First, online teachers and moderators should be aware that there is no contradiction between social interaction and learning processes. Most research results (including ours) show that teachers find it difficult to change their dominant role to that of moderators and facilitators of learning. As a result, students neither have enough opportunities to interact with each other, nor are they directed to develop self initiative and make active contributions to the collaborative learning process. Social behavior is a natural human need and is acknowledged as an important factor in the development of learning processes. It is claimed to be particularly important in technology-mediated learning situations (Harasim et. al, 1995).

In their tutoring and moderating of virtual learning groups, teachers should explicitly support creation of a social climate with learning groups. With respect to the teachers' role:

- Teachers should moderate the group's work in a way that enables students to interact. They should act mainly as facilitators of processes and they minimize their interventions so as to allow students to gain knowledge from each other and manage discussions independently. They should therefore refrain from dominating the discussion and from interacting mainly with individual students (the one -to-many teacher-centric template typical of the frontal classroom), encouraging instead dense student-to-student interactions.

- They should also encourage participants to act friendly with each other and create a relaxed and calm atmosphere.

- Online course moderators should be attentive to participants' social needs,

International Review of Research in Open and Distance Learning 
The Development of Social Climate in Virtual Learning Discussion Groups 15

and offer a legitimate platform for messages (or parts in messages) that have social rather than solely content significance.

- It is crucial to enhance the social atmosphere by using supportive feedback, discussing with the group ways to facilitate the creation of social interactions, emphasizing the importance of peer feedback, and by encouraging students to relate to each other during the learning activities and beyond.

Implications of our observations at the level of the pedagogical rationale of online courses are related to aspects such as the character of the assignments included in the course, the focus of the discussion forums, or the identities assumed by the students. Examples of these implications are:

- Group work should be encouraged as a powerful configuration for the accomplishment of learning tasks (Scardamalia \& Bereiter, 1994). Course developers should aim to define learning assignments that demand varied forms of interaction and collaboration for their completion.

- Teachers should implement learning strategies that support communication such as appointing students to moderate discussion groups (Harasim et. al, 1995); or encouraging students to help each other and to refer to each other instead of looking at the instructor as the only partner for dialogue and the only resource for help.

- Course developers should pay particular attention to the creation of a varied range of virtual spaces in order to respond to different social needs evolving during the group's work.

- A distance learning course should include a social forum as a place for social integration of the learning group. Moreover it should enable participants to contact each other for multiple purposes rather than solely for learning purposes.

- It should also include a special place - or forum - in which students can seek for meaningful and contextual (e.g., technical, content-related) help.

- In order to achieve the degree of intimacy required for significant exchanges within online interactions, it is recommended that the number of participants be limited to 20 .

As in many other educational attempts to assimilate innovations, appropriate teacher training is a key factor in the design of successful models of socially sound technology based learning. It is obvious that most current teachers' pre-service preparation, and subsequent in-service courses were devised in reference to traditional educational technology and settings (e.g., printed materials, frontal lectures, and face-to-face group work). Thus, they are not familiar with the 
processes, interaction patterns, features and possibilities of technology-mediated educational transactions. Teacher training programs for online learning should include moderation skills that foster integration of social interactions (e.g., positive emotions, humor, exchange of personal notes) within the task-related discussion process.

Students' learning experiences are obviously shaped by the features of the traditional classroom milieu. However, it is reasonable to expect that those students who have spent time communicating and plying via the Internet have already developed intuitions and skills regarding social functioning in virtual spaces. But this is surely not the case for all students or for social interactions embedded in formal learning tasks. At this level, student training is required. Students' digital social behavior may be improved by teaching them new communication skills that are relevant to the participation in virtual discussion groups, such as how to bridge between colloquial spoken and written language, how to express feelings by symbolic means, how to participate in asynchronous discussions (e.g., to reflect on other peoples and their own previous messages, maintenance of parallel lines of discussion), and how to moderate peer-group discussions.

Finally, more research is needed. The study of social climate developing in virtual learning groups is still incomplete. At this stage we are mainly engaged in the identification of emerging modes of social activity facilitated by the use of ICT, and in the definition of relevant research questions. The studies reported in this paper represent an attempt to elucidate some of these new and interesting questions, and contribute to the development of virtual learning activities that support social climate in online courses.

International Review of Research in Open and Distance Learning 
The Development of Social Climate in Virtual Learning Discussion Groups 17

\section{References}

Amidon, E. J., Flanders, N.A. (1967). Interaction analysis as a feedback system. In E. Amidon, and J. Hough (Eds.), Interaction Analysis: Theory, Research and Application, Reading, MA: Addison Wesley.

Anderson, T., \& Kanuka, H. (1997). Online forums: new platforms for professional development and group collaboration. [Online] Available at: http://www.jcmc.huji.ac.il/vol3/issue3/:

Baudin, B. (1999). Keeping online asynchronous discussions on topic. JALN, 3(2). [Online] Available at: www.aln.org/alnweb/journal/vol3_issue2/beaudin.htm.

Bonk, C., Kirkley, J., Hara, N., \& Dennen, V. (2000). Advances in Pedagogy: Finding the Instructor in post-secondary online learning. Paper presented at the annual meeting of the American Educational Research Association, New Orleans, LA. [Online] Available at: http://www.indiana.edu/ bobweb/temp/online_ped.pdf.

Burbules, N. (forthcoming). Like a version: Playing with online identities. Educational Philosophy and Theory. [Online] Available at: http://faculty.ed.uiuc.edu/burbules/ncb/papers/dre

Chan, T., \& Rapman, J. (1999). Flow in web based instructional activity: An exploratory research project. International Jr. of Educational Communications, 5(3), p. 225-237.

Daher, W. (2000). Verbal interaction patterns in the Mud class. Unpublished M.A. Thesis, School of Education, Tel Aviv University (Hebrew).

Flanders, N.A. (1967). Teacher influence in the classroom. In E. Amidon, and J. Hough (Eds.), Interaction Analysis: Theory, Research and Application, Reading, MA: Addison Wesley.

Hara, N., Bonk, C., \& Angeli, C. (2000). Content analysis of online discussion in an applied educational psychology course. Instructional Science, 28, p.115152 .

Harasim, L. (1990). Online education. NY: Praeger Publishing.

Harasim, L., Hiltz, S., Teles, L., \& Turoff, M. (1995). Learning networks: a field guide to teaching \& learning online. Cambridge, MA: MIT Press.

Henri, F. (1991). Computer conferencing and content analysis. In A. Kaye (Ed.), Collaborative Learning through Computer Conferencing. Heidelberg, FRG: Springer-Verlag.

Hiltz, S. (1995). The virtual classroom: learning without limits via computer networks. Norwood, NJ: Ablex Publishing.

Jiang, M., \& Ting, E. (2000). A study of factors influencing students perceived learning in a Web-based course environment. International Jr. of Educa- 
The Development of Social Climate in Virtual Learning Discussion Groups 18

tional Telecommunication, 6(4), p. 317-338.

Kiesler, S., \& Sproull, L. (1992). Group decision making and communication technology. Organizational Behavior and Human Decision Processes, 52(1), p. $96-123$.

Korhonen V. (2001). Situated and socially shared cognition in practice: designing a collaborative network learning experience for adult learners. In C. Montgomerie, \& J. Vitely (Eds.), Proceedings of Ed-Media 2001, AACE.

Murphy, T. (1995). A Quantitative analysis of instructor-student verbal interactions in a simultaneous two way audio-video distance education setting. Unpublished Doctoral Dissertation, Texas A\&M University, College Station. [Online] Available at: Http://aged.tamu.edu/faculty/murphy/disserta/disintro.htm.

Nachmias, R., Mioduser, D., Oren, A., \& Ram, J. (2000). Web-supported emergent collaboration in Higher Education courses. Educational Technology \& Society, 3(3), p. 94-104.

Pankraz, A. ( 1967. Verbal interaction patterns in the classrooms of selected physics teachers. In E. Amidon, and J. Hough (Eds.), Interaction Analysis: Theory, Research and Application, Reading, MA: Addison Wesley.

Oren, A., Nachmias, R., Mioduser, D., \& Lahav, O. (2000). Learnet - a model for virtual learning communities in the World Wide Web. International Journal of Educational Telecommunication, 6(2), p. 141-158.

Oren, A. (2001). Teachers learn to communicate. Iunim Betchnologia Ubemadaim, 34, p. 12-16. (In Hebrew).

Parks, R. M., Floid, K. (1996). Making friends in cyberspace. Journal of Computer Mediated Communication, 1 (4). [Online] Available at: Http://www.ascusc.org/jcmc/vol1/issue4/par

Rozner, E. (2000). Collaborative activity as promoting a learning process a case study of online computer conferencing. Unpublished M.A. Thesis, School of Education, Tel Aviv University (Hebrew).

Scardamalia, M., \& Bereiter, J. (1994). Computer support for knowledgebuilding communities. The Journal of the Learning Science, 3 (3), p. 265283.

Schnarch, D. (1997). Sex, intimacy, and the Internet. Journal of Sex Education and Therapy, 22(1), p. 15- 20.

Sharan S. (1994). Handbook of cooperative learning methods. Westport, CT: Greenwood.

Sherry, L. (2000). The nature and purpose of online discourse: a brief synthesis of current research as related to the Web project. International Jr. of

International Review of Research in Open and Distance Learning 
The Development of Social Climate in Virtual Learning Discussion Groups 19

Educational Telecommunication, 6 (1), p. 19-51.

Sherry-Steinberg, O. (2000). The development of social climate in discussion forums integrated in different models of distance learning courses. Unpublished M.A. Thesis, School of Education, Tel Aviv University (Hebrew).

Sotillo, M. S. (2000). Discourse functions and syntactic complexity in synchronous and asynchronous communication. Language learning \& Technology, 4(1), p. 82-119.

Sproull, L., \& Kiesler, S. (1991). Connections: new ways of working in the networked organization. Cambridge, MA: MIT Press.

Tsur, O. (2000). The influence of student anonymity and teacher guidance on the social and cognitive nature of educational net conferencing. Unpublished M.A. Thesis, School of Education, Tel Aviv University (Hebrew).

Turkle, S. (1995). Life on screen: Identity in the age of Internet. NY: Simon and Shuster.

Varsidais, B., (2000). Constructivism versus objectivism: implications for interaction, course design, and evaluation in distance education. International Jr. of Educational Telecommunication, 4 (1), p. 339-362.

Walther, J. (1996). Computer mediated communication: Impersonal, interpersonal, and hyperpersonal interaction. Communication Research, 23(1). p. 3- 43.

Walther, J., Anderson, J., \& Park, D. (1994). Interpersonal effects in computermediated interaction: a meta-analysis of social and antisocial communication. Communication Research, 4, p. 460-487.

Wegerif, R. (1998). The social dimension of Asynchronous Learning Networks.

[Online] Available at: http://www.aln.org/alnweb/journal/vol2_issue1/wegerif.htm.

Citation Format

Oren, Avigail , Mioduser, David \& Nachmias, Rafi (April, 2002) The Development of Social Climate in Virtual Learning Discussion Groups. International Review of Research in Open and Distance Learning: 3, 1. http://www.icaap.org/iuicode?149.3.1.x 